\title{
Distributions and Relations:
}

\section{A Hybrid Account}

\section{Introduction}

There is a deep, perhaps even fundamental, divide amongst political philosophers of an egalitarian stripe. On the one hand, there are so-called distributive egalitarians, who hold that equality obtains within a political community when each of its members enjoys an equal share of the community's resources.' On the other hand, there are so-called social egalitarians, who instead hold that equality obtains within a political community when each of its members stands in certain relations to other members of the community, such non-domination and lack of oppression, for example. ${ }^{2}$ As egalitarians, then, we must choose between these two rival positions. Does equality consist in the equal distribution of resources or certain relations amongst individuals?

Our first aim in this paper is to cast doubt on the helpfulness of characterizing the debate in this way-that is, in terms of mutually exclusively claims about the nature of the demands of equality. Framing the debate in these terms can hide some similarities between these views, delaying progress with a range of social and political issues.

Our second aim is to reconstruct the debate between distributive egalitarianism and social egalitarianism in more precise terms, so that disagreements between the contributions of advocates on either side are easier to evaluate. Our strategy makes use of the idea that reasons should be the unit of analysis for our purposes. Accordingly, whilst many political theorists characterize the debate in terms of the nature of the demands of equality, we propose re-articulating it in terms of claims about reasons. Instead of analyzing the concept of equality, we must examine the reasons in favour of equality. When put in these terms, distributive egalitarianism holds that we have reasons to secure an equal distribution of resources amongst members of a community, and social egalitarianism holds that we have reasons to ensure certain relations between them.

When stated in this way, distributive egalitarianism and social egalitarianism are not rival positions, in the sense that we must choose between them. We may have reason to secure an equal distribution of resources and we may have reason to ensure certain relations. Under some conditions, the two claims may even be supportive, such that we have reason to secure an equal distribution of resources because we have reason to ensure certain relations (Anderson, 1999: 313-14; Scheffler, 2005). Our third aim is to delve deeper 
into this possibility, as well as more generally to explore the complex relationship between these two types of reasons. This is an under-explored question. ${ }^{3}$ The lack of literature here reflects the fact that many commentators have mistakenly been drawn to the idea that distributive egalitarianism and social egalitarianism offer mutually exclusive possibilities that we must choose between.

We develop a hybrid account that incorporates both distributive egalitarianism and social egalitarianism. This account reflects the fact that both positions describe fundamental reasons, which may sometimes conflict, but often are mutually supportive of each other. We call this account hybrid so as to emphasize how distributive egalitarianism and social egalitarianism continue to make distinct claims and, thus, also to highlight distinct sources of our fundamental moral reasons. By shedding light on the relationship between distributive and social egalitarianism, we contribute to developing an attractive egalitarian view.

It is worth noting that both distributive egalitarianism and social egalitarianism are themselves diverse positions. Famously, there is widespread disagreement amongst distributive egalitarians about what makes a distribution of resources equal, in the relevant sense. Whereas some claim that it is equal when each individual enjoys equally valuable opportunities for preference-satisfaction, others deny this. ${ }^{4}$ Similar disputes surround the conditions under which deviations from equality that result from choice may remain just (Dworkin, 2011: ch. 10). Similarly, there is room for widespread disagreement amongst social egalitarians about what makes relations between individuals valuable, in the relevant sense. Whereas some focus exclusively on the demands of democratic citizenship, others incorporate a concern for other features of potentially valuable relations between individuals. ${ }^{5}$ There is also disagreement about the site of the demands of each position. Do they apply only to society's basic structure or also to an individual's choices within that structure? $?^{6}$

Many of these disagreements are germane to our task. To understand the relationship between distributive egalitarianism and social egalitarianism, we need to understand which versions of the two positions we are considering. One way to proceed, then, is to reflect carefully upon the various relationships that hold between various versions of each position-that is, to conduct a kind of literature review. However, we pursue a different route, operating with what we take to be the most attractive versions of each view. In effect, our strategy is to reconstruct these positions in the most plausible light. 
In section 2, we describe our strategy, clarifying how conceptual analysis differs from normative reason-based analysis. In section 3, we describe how distributive egalitarian reasons and social egalitarian reasons are mutually supportive in a range of significant cases. This convergence is the core of our hybrid account. In the next two sections, we assess its limits. In section 4, we propose a novel and sophisticated explanation of why some of the reasons in favour of distributive egalitarianism cannot be reduced to social egalitarian reasons. In section 5, we draw upon insights from a debate in another area of normative philosophy to explain why some of the reasons in favour of social egalitarianism cannot be reduced to distributive egalitarian reasons. We briefly conclude in section 6 .

\section{Concepts and Reasons}

The disagreement between distributive egalitarianism and social egalitarianism is often characterized as one about the nature of equality or, more specifically, as one about the nature of the demands of equality. When presented in this way, it involves a conceptual dispute.

It is tempting to think that conceptual disputes of this kind are central to many, if not all, political disputes. Perhaps this is because, when two parties disagree, it often seems sensible to interrogate the foundations of that disagreement by identifying and evaluating the concepts that each relies upon. For example, when G. A. Cohen attempts to show that his so-called egalitarian ethos does not restrict an individual's freedom, he does so by investigating the concept of freedom and the nature of its demands (2008: ch. 5). Many other moral and political disputes seem to admit of the same kind of resolution. Philosophical disputes about human rights seem to admit of the same form, with authors competing over the concept of human rights. ${ }^{7}$ For this reason, it is not surprising that some authors like to articulate the disagreement between distributive egalitarianism and social egalitarianism in this way.

Though there may be some benefits to adopting this approach, it is not always helpful to do so if our aim is specifically to make progress with understanding and resolving normative disagreements about our reasons for actions, duties, and rights (Raz, 1990: 11-12). In short, if our concern is with our reasons for action, we often do better to present disputes in these terms rather than in terms of claims about concepts, which are less immediately relevant to our purposes. This is not to deny that it can sometimes be helpful to theorize about concepts (both within normative theory and in philosophy and politics more generally). For example, it can sometimes be important for a political movement to (re)claim concepts or terms, such as freedom, from their 
opponents. Conceptual analysis can help with this task. Our claim is more modest: if we are interested in normative disagreements, we should be interested in the analysis of concepts only in so far as it aids our investigation into our reasons for action. When conceptual analysis of this kind fails to perform this role - say, because it obscures issues of interest or invites confusion - we should abandon it, so as to focus our efforts more directly on our reasons for action.

Conceptual analysis has limited use in normative investigations. This is because of the possibility of verbal disputes. A verbal dispute is an apparent dispute that arises wholly in virtue of linguistic disagreement about the meaning of an expression, and not at all in virtue of a substantive nonlinguistic disagreement (Chalmers, 2011: 521-6). If Angela fails to reveal a piece of information, and Betty and Cathy both believe for the same reasons that, in doing so, she acts morally wrongfully, but they disagree about whether or not to call it a lie, then they are having a verbal dispute. As David Chalmers points out, verbal disputes of this kind are 'usually impediments to understanding. In effect, they are obstacles that we do better to move beyond, in order that we can focus on the substantive issues regarding a domain' (2011: 517).

The point is not that, when we overcome verbal disputes, we always realize that there is no underlying disagreement. Sometimes this is the case, such as in Angela's case; but sometimes it is not, such as would have been the case if Betty and Cathy had also disagreed about whether Angela had acted wrongfully. It is difficult to determine whether there is an underlying disagreement between parties unless we present it in a way that avoids the possibility of verbal disputes.

These claims cast further doubt on the relevance of conceptual analysis to normative investigations. In the same vein, and responding to Cohen's claim that his egalitarian ethos does not restrict an individual's freedom, Paula Casal writes:

...starting with a concept, such as that of acting freely, may not be the best way to arrive at a sensible conclusion about what we should do as a society regarding economic incentives or other inequality-generating practices. The same applies to other decisions society must make, such as same-sex marriage. We should decide on it through normative considerations and not by analysing how the term 'marriage' is employed (2013: 9). 
The disagreement between distributive egalitarianism and social egalitarianism is vulnerable to these problems. Though proponents on all sides claim to be interested in normative questions, it is not uncommon for them to present their views as claims about the nature of equality. ${ }^{8}$ This can be confusing since it is possible that distributive egalitarians and social egalitarians disagree about the nature of equality, but both believe for the same reasons that certain social and economic practices are just or unjust. Again, we do not claim that this is in fact always the case. The point is that it is difficult to determine whether there is an underlying disagreement, and where exactly it lies, unless we present the debate in a way that avoids the possibility of this verbal dispute. ${ }^{9}$

We therefore propose re-stating each position in terms of reasons, which are a more helpful unit of analysis for normative investigations..$^{10}$ The kind of reasons to which normative analysis appeals are reasons for action. These are considerations that count in favour or against doing something (instead of reasons for believing, having attitudes, or merely valuing something) (Scanlon, 1998). Construed in this view, distributive egalitarianism claims that we have reason to secure for each member of the community an equal share of its resources, and social egalitarianism claims that we have reason to ensure that each member of the community stands in certain relations to other members of the community.

In defending the importance of focusing on reasons, we do not subscribe to any controversial claims about either the metaphysical priority of reasons over concepts or whether all reasons derive from concepts. ${ }^{12}$ For example, it is consistent with our analysis that an individual can have an egalitarian reason to do $\mathrm{X}$ only if the nature of the concept of equality is such that it provides her with that reason. ${ }^{13}$ Our claim is rather more modest, namely that, as a presentational matter, it can be helpful to re-state distributive egalitarianism and social egalitarianism in terms of reasons, since doing so enables us to avoid potential verbal disputes.

Some will resist our characterizations of distributive egalitarianism and social egalitarianism. Most notably, a leading proponent of distributive egalitarianism, Cohen, very seldom states his views in terms of reasons (for action). ${ }^{14}$ This is not accidental. Cohen is interested not only in normative questions-that is, in questions about our reasons for actions, duties, and rights-but also in questions in value theory-that is, in questions about the goodness or badness of various states of affairs (Williams, 2008). On his view, we have reason to secure for each member of the community an equal share of its resources, and we should regret it-indeed, deem it an injustice-when members fail to get that share (even if this is unavoidable). ${ }^{15}$ Despite this, our 
statement of distributive egalitarianism corresponds to an important part of Cohen's position, and presumably he accepts that we have reason to secure for each member of the community an equal share of its resources (Segall, 2016). As a result, we put aside this complication.

To conclude this section, let us draw attention to the fact that our argument here is in one respect very ambitious-more ambitious than necessary for the central claims that we advance in the rest of this paper. More specifically, one does not need to embrace our opposition towards the normative importance of conceptual analysis in order to accept that, because it enables us to avoid verbal disputes, it can be helpful to re-state distributive egalitarianism and social egalitarianism in terms of reasons. Though unnecessary, the more ambitious claims remain is this paper since we believe that they help to explain a great deal of confusion within this literature, as well as the resulting impasse between some distributive egalitarians and some social egalitarians.

\section{Defending the Hybrid Account}

When stated in terms of reasons, it is difficult to see why distributive egalitarianism and social egalitarianism might be thought mutually exclusive. The truth of distributive egalitarianism does not seem to provide any evidence against the truth of social egalitarianism, and vice versa. We may-indeed, we believe that we do-have both sets of reasons: reasons to distribute resources equally and reasons to ensure certain relations between members of the community. Under at least some conditions, however, the relationship between these two reasons is more intimate. In particular, there are cases in which we have reasons to distribute resources equally partly because we have reasons to ensure certain relations between community members (Schemmel, 2011). To see this, let's consider the following familiar example (Dworkin, 2000: $12-13):^{16}$

Inheritance: Following the death of their mother, siblings Dan and Erika must decide how to split their inheritance.

Other things being equal, if Dan were to retain a greater-than-equal share of the inheritance, this would display a lack of equal concern and respect for Erika, who would then receive a less-than-equal share. ${ }^{17}$ In this case, the siblings have a reason to distribute the assets equally that partly derives from their reason to ensure certain valuable relations. We recognize that there is more to say here, and we return to this case later in this section, as well as in subsequent sections. For now, our aim is to illustrate the fact that social egalitarianism has certain 'distributive implications' (Scheffler, 2005: 21). 
At this stage, it makes sense to distinguish different kinds of valuable relations and, correspondingly, to distinguish the different kinds of distributions that are necessary for these relations to exist (Lippert-Rasmussen, 2015a: 183). We shall focus on two possibilities, though we acknowledge that there are others. $^{18}$

First, as Samuel Scheffler points out, there is something valuable in those relations between individuals that are in certain crucial respects at least, unstructured by differences of rank, power, or status' (2005: 17). Valuable relations of this kind are possible only if (and so far as possible) we distribute resources such that each individual enjoys continued access to some basic set of goods, including, for example, those that are necessary to appear in public without feeling a sense of shame.

In addition to this, our concern for these kinds of relations also provides grounds upon which to object to highly unequal distributions of resources, even if no one is particularly badly off. This is because, as John Rawls notes, highly unequal distributions may predictably lead some individuals to feel that their interests are not properly being taken into account, which is an obstacle to the kind of relations Scheffler describes (1999: 478-9). This worry remains even if the distribution of resources meets other moral standards (such as the satisfaction of Rawls's difference principle), as well as if there is no actual domination of those with less by those with more (Axelsen and Nielsen, 2015: 419-22). It is important to note that this point has force in a wide range of social contexts and, in particular, to highlight how certain distributions can help to create valuable relations between strangers. Relations of gratitude, for instance, flourish against a background of equality:

Gratitude: Mike is at home with his ill children. Betty offers to run to the market to buy groceries for him. As a result, Mike contracts a debt of gratitude to Betty.

Gratitude involves not only a duty to repay the resources that Betty spent in assisting Mike, but also a disposition to help her when she is in need. Relations of gratitude can obtain only in the absence of great distributive inequalities. People who possess many more resources than others might never need help from them (although they might need help from others who have more or less as much as they have). In this sense, those who have less might not have the opportunity to initiate relations of gratitude. At the same time, those who have less might not welcome the help of those who have more because they anticipate that they will be unable to discharge their duty of gratitude (Herman, 2013). To the extent that we have reasons to value relations of gratitude, we have reasons to reduce great distributive inequalities. 
The prior discussion reveals how distributions of resources will threaten certain valuable relations if they (i) leave some individuals beneath the sufficiency threshold, and/or (ii) are highly unequal. However, as critics correctly note, it does not follow from this that we have reasons to favour egalitarian distributions as such (Anderson, 1999: 326). This is because it may be possible to realize these valuable relations in the presence of inequality, providing that the inequality leaves no one beneath the sufficiency threshold and is not too great. In order to establish the case in favour of egalitarian distributions as such, we must turn to a second set of arguments.

Our argument begins with the idea that there is something valuable about the relations between individuals who enjoy access to their just entitlements, where we determine these in a way that is prior to, and independent of, certain claims about the value of various relations. Relations of this kind are valuable because each individual can justify to others why she is morally permitted to retain the resources she possesses. The intuition on which this relies is that, if an individual possesses a resource that morally belongs to another, this corrupts the value of their relations. This can prevent them from forming, and enjoying the benefits of, a particularly valuable kind of justificatory community (Cohen, 2008: 43).

Two conditions are important here. ${ }^{19}$ First, in order for a group of individuals to enjoy justificatory community, each individual must sincerely believe that she is morally permitted to retain the resources she possesses. It's odd to think that we can enjoy justificatory community with people who simply don't care about whether the advantages they enjoy are morally justified. Second, in order for a group of individuals to enjoy justificatory community, their sincere beliefs must meet an objective moral standard. Even if they are able to realise other kinds of goods, there can be no justificatory community between a wealthy Aristocrat and an impoverished peasant, even if both sincerely but mistakenly believe that each enjoys her just entitlements. This is because their sincere beliefs fail to meet the relevant objective moral standard. This second condition reveals how the notion of justificatory community has objective conditions, and so is not a wholly psychological or subjective phenomenon. ${ }^{20}$

In order to fill out these objective conditions, it is necessary to invoke a theory that specifies each individual's distributive entitlements. We believe that distributive egalitarianism best fulfils this role. ${ }^{21}$ On this view, we have a reasons to secure an equal distribution of resources because we have a reason to ensure that members can form, and enjoy the benefits of, a justificatory community (Schemmel, 2011). As Harry Brighouse and Adam Swift point out, 
...a society that permits unjustified or illegitimate inequalities between its members just is one whose members are not treating one another, relating to one another, as equals. The distributions themselves express inegalitarian relationships. To live with others in an unequal society on terms that cannot be justified to those who have less is not merely a distributive failure; it is also a failure of relationship (2014: 27).

In support of this claim regarding the credentials of distributive egalitarianism, let's return to Inheritance. Absent some special justification, if Dan were to retain a greater-than-equal share of the inheritance, this would corrupt the value of their relations. ${ }^{22}$ Perhaps their relationship would merely become less amicable; perhaps things would become more hostile.

The resulting diminished value of their relations partly reflects the fact that, if the inheritance were distributed in this way, Dan would be unable to justify his holdings to Erika. In an important respect, therefore, the value of their relations depends upon the equal distribution of resources between them. Moreover, what matters is that Dan and Erika enjoy their just entitlements, and not simply that they each enjoy continued access to some basic set of goods or that there are no large inequalities between them. We can infer this from the fact that these problems remain even if both Dan and Erika are welloff in absolute terms, and even if their inheritance is small such that its unequal distribution would not lead to the risk of domination.

Distributions can corrupt the value of relations in two distinct ways. This is because certain distributions of resources may be both (i) constitutive of certain valuable relations; and (ii) a pre-condition for certain valuable relations. Regarding the first, there is something intrinsically valuable about relations that are mutually justifiable in the sense described. It is intrinsically valuable for individuals to stand in relations whereby each is able to justify her choices to others, including her choices to retain possession of certain resources. This concern for mutual justifiability is linked to our weighty interest in being able to treat others, and be treated by others, as having acted justly.

Regarding the second, an equal distribution of resources can serve as a platform from which more valuable relations, such as friendship, can develop. This is particularly clear in Inheritance where, if Dan were to retain more of the inheritance than Erika, this would prevent them from enjoying as valuable a relationship. 
This result is particularly interesting, since it may be possible to generalize the argument to the political sphere. When this is the case, we should favour an equal distribution of society's assets on the grounds that it is a precondition for individuals' enjoyment of civic friendship. ${ }^{23}$ In other words, unequal distributions of resources corrupt societal relations because they effectively prevent the possibility of civic friendship. Admittedly, this is controversial, and any adequate defence of this claim would require a discussion of the nature and value of civic friendship, as well as a discussion of how this differs from mutual justifiability. Though we are sympathetic to the possibility of such an argument, for reasons of space, we do not pursue it here.

Critics of these arguments will challenge distributive egalitarianism's ability to play these roles, denying that there is anything distinctly valuable about the relations constituted or made possible by an equal distribution of resources in comparison with those constituted or made possible by a sufficientarian distribution of resources (Anderson, 1999: 326). Perhaps individuals can justify retaining a greater-than-equal share of resources providing that the inequality is not great and that every other individual is above some threshold. Even if this is false, perhaps these inequalities don't much affect the value of individuals' relations.

To see the force of this objection, we can take the example of buying rounds of drinks, where it typically does not threaten certain valuable relations between those in the round if those drinking cheaper drinks over-pay and those drinking more expensive drinks under-pay. Even putting aside that they may be the product of responsible choice, the inequalities generated by this practice clearly do not threaten certain valuable relations. The alleged consequence of this objection is that, from the perspective of valuable relations, there is nothing distinctive about securing an equal distribution of resources (Cohen, 2008: ch. 8 and 2009).

This case has some force, and we agree that, when buying rounds, we ought not to worry about the small inequalities doing so may produce. However, this case has three features that make it sui generis. First, the absolute costs involved are very small and so too are the associated inequalities to which they may give rise. The injustices involved are therefore likely to be trivial and not worth caring about. This explains why, in Inheritance, we might not be concerned if Dan were to retain a very slightly larger than equal share of the inheritance (e.g. if Dan's allocation were worth $£ 10,010$ but Erika's were worth only $£ 9,990) .{ }^{24}$ However, the same is not true when we consider the distribution of society's resources more generally, where even small inequalities make an enormous difference to individuals' lives. 
Second, we have independent reasons to favour buying in rounds, relating to its convenience and the expression of community that it involves. Even if the inequalities to which the practice gives rise are in one way problematic, they remain unobjectionable given our other reasons to support buying in rounds. We leave open the possibility that the same is true in other social and political settings.

Third, and related to the previous point, relations involving civil friendship do not involve the level of intimacy that are typical of friends buying rounds. Scorekeeping with friends might taint the relationship, but might be less problematic in situations that involve little intimacy (Scheffler, 2015; Brighouse and Swift, 2006).

There is also a more general reply to the present objection, which holds that there is nothing distinctly valuable about the relations constituted or made possible by an equal distribution of resources. This reply makes use of the fact that, even if distributive egalitarianism were ill-equipped to play the role that we have attributed to it, this would be of only limited significance to our overall argument. This is because the objection does not challenge the more fundamental idea that we have a reason to care about the distribution of resources that derives from our reasons to ensure certain relations between members of the community.

Our argument is significant in part because we add a further layer to the analysis of the complex relationship between distributive egalitarianism and social egalitarianism. Our core claim here is that, in at least some significant cases, we should adopt a hybrid view that incorporates concern for both distributive egalitarianism and social egalitarianism. Moreover, in some cases, we can enhance our understanding of social egalitarianism by reflecting more carefully about the value in the kinds of relations that different distributions of resources constitute and make possible.

To conclude this section, we discuss the implications of our analysis for a familiar case that is often thought to divide distributive egalitarianism and social egalitarianism: ${ }^{25}$

Gambler: As a result of gambling, Fiona becomes destitute, while others in her community continue to enjoy a high level of wealth.

From the perspective of distributive egalitarianism, it appears that Fiona would not be morally entitled to assistance if she had squandered her equal share of resources. On this view, we have reasons against forcing others to compensate Fiona, as doing so would mean that Fiona enjoys a greater-thanequal share of resources and that others enjoy a less-than-equal share of 
resources. Intuitively, this conclusion is too harsh on Fiona, and this is a potential embarrassment for distributive egalitarianism (Fleurbaey, 1995). By contrast, from the perspective of social egalitarianism, Fiona is clearly morally entitled to assistance, as doing so is necessary to preserve certain valuable relations between Fiona and other members of her community. In this way, distributive egalitarianism and social egalitarianism offer very different diagnoses of cases such as Gambler. This conclusion supports the concern that the relationship between distributive egalitarianism and social egalitarianism is not as intimate as our arguments seem to suggest.

Our response is to deny that distributive egalitarianism must have the implications that were alleged above. For example, one variant of distributive egalitarianism holds that the costs of compensation should be internalized by those responsible for creating its demand (Williams, 2006). In Gambler, we could achieve this through special taxes on gambling, compulsory insurance, or even an outright ban. Here is not the place for a complete defence of the plausibility of this strategy. Rather, what matters is that this reply exploits the fact that it is consistent with the claim that we have reasons to secure an equal distribution of resources that we also have reasons to limit individuals' use of those resources, as well as the level of disadvantage to which various choices may give rise (Olsaretti, 2009; Stemplowska, 2016; Williams, 2006). By pursuing this route, defenders of distributive egalitarianism are able to articulate its demands in a way that coheres with the demands of social egalitarianism, such that we need not have to pick between the two.

\section{Can Social Egalitarianism Subsume Distributive Egalitarianism?}

Our aim in the previous section was to highlight the complex and sometimes intimate relationship between distributive egalitarianism and social egalitarianism. Our aim in this and the next section is to examine the extent of this reconciliation. To aid with this task, we consider two opposing possibilities. The first appeals to the idea that social egalitarianism can fully subsume distributive egalitarianism; and the second appeals to the idea that distributive egalitarianism can fully subsume social egalitarianism. We contend that neither of these ideas is plausible. This conclusion is important in so far as it reveals that distributive egalitarianism and social egalitarianism are distinct sources of moral reasons. In turn, this supports the conclusion that we must embrace a hybrid view.

We begin with the claim that we can fully reconcile distributive egalitarianism and social egalitarianism by subsuming the former under the latter. According to this view, we have reasons to secure an equal distribution of resources only because we have reasons to ensure certain relations. If correct, distributive 
egalitarianism would be only instrumentally valuable to our pursuit of social egalitarianism. We might think that the argument in the previous section lends some support to this idea. There, we appealed to Inheritance in order to show how we have reasons to secure an equal distribution of resources that derive from our concern for certain relations.

We must reject this possibility. Whilst our reasons to secure an equal distribution of resources may derive from our concern for certain relations, this is not always the case. Sometimes, we have independent reasons to secure an equal distribution of resources that in no way derive from our concern for certain relations - that is, that in no way derive from social egalitarianism.

To illustrate this point, let's again return to Inheritance, where we earlier concluded that, absent some special justification, if Dan were to retain a greater-than-equal share of the inheritance, this would corrupt the value of their relations. This analysis is in one respect too shallow. This is because it is important also to examine why this would corrupt the value of their relations. The answer lies in the fact that, in acting in this way, Dan would deny Erika her just entitlements and would therefore treat Erika unjustly. However, if we are to make sense of this idea, then we must suppose that there is a prior theory of just entitlements to which we can appeal. Again, distributive egalitarianism may claim to play this role.

Our analysis of Inheritance reveals that there are independent reasons to care about distributions. These reasons are prior to, and thus do not derive from, our concern for certain relations. Unequal distributions corrupt the value of relations in this way only because we have an independent reason for condemning those distributions as unjust. Thus, though we might say that their tendency to corrupt relations is an additional evil associated with unequal distributions, we cannot say that a distribution is unjust merely by virtue of the fact that it corrupts relations. This is because its corrupting nature is attributable to its injustice: if the distribution were not unjust, its maintenance wouldn't corrupt relations (Fourie, 2012: 16).

We can further clarify this relationship between distributions and relations by reflecting upon the following example, introduced by Cohen in a discussion of exploitation:

Suppose that whoever is in a position to do so distributes guns unequally, that is, to some people but not to everybody, and that guns enable those who have them to engage in highway robbery. Suppose that an equal distribution of guns would have meant no highway robbery, because of mutual deterrence, and suppose also 
that the only relevant use of guns is to commit or deter highway robbery (1995: 198).

In this case, we have two injustices. As Cohen notes,

We can say that highway robbery is unjust and that an unequal distribution of guns is unjust. And we can say that the unequal distribution of guns is unjust because it enables highway robbery, meaning thereby that the gun inequality owes its injustice to whatever it enables: it counts as unjust because of the injustice (highway robbery) that it facilitates (1995: 198).

Cohen's analysis is relevant to our purposes, since we can draw similar conclusions with respect to the relationship between distributions-based injustice and relations-based injustice. To paraphrase Cohen,

We can say that certain relations are unjust and that a given distribution of resources is unjust. And we can say that a given distribution of resources is unjust because it enables certain relations, meaning thereby that the maldistribution of resources owes its injustice to whatever it enables: it counts as unjust because of the injustice (in certain relations) that it facilitates.

We must therefore reject the idea that we have reasons to secure an equal distribution of resources only because we have reasons to ensure certain relations. ${ }^{26}$ This conclusion is important, for it reveals that both sets of reasons are fundamental, in the sense that they are not merely instrumental reasons. An implication of this is that we have two distinct sources of fundamental moral reasons. Distributive egalitarianism provides us with fundamental reasons to secure an equal distribution of resources; and social egalitarianism provides us with fundamental reasons to ensure certain relations. Under at least some conditions, these two sets of reasons are mutually supportive. However, under other conditions, they remain more distinct. The hybrid account that we propose reflects this complexity in our moral landscape.

\section{Can Distributive Egalitarianism Subsume Social Egalitarianism?}

Let us turn now to the opposing idea, that distributive egalitarianism can fully subsume social egalitarianism. According to this view, when distributive egalitarianism states that we ought to secure an equal distribution of resources, we should interpret this in a way that is consistent with the demands of social egalitarianism. More specifically, distributive egalitarians might broaden the idea of a 'resource' so as to include certain relations or certain properties of relations-we can call these 'social resources' (Cordelli, 
2015). This move enables us to make sense of the idea that, when an individual is denied certain valuable relations with others, she is denied an important resource-a social resource-whose distribution may be important to distributive egalitarians.

To illustrate this argument, let's consider the following case:

Couple: Mary and John relate to each other such that each enjoys an equal degree of social standing. Things then change in a way that then results in Mary looking down upon John as her inferior, such that John now enjoys a reduced degree of social standing. ${ }^{27}$

Social egalitarians rightly conclude that Couple involves an injustice. One explanation for this is that Mary and John no longer stand in certain valuable relations to each other. But, distributive egalitarians can reach a similar verdict by embracing a broadened account of resources. Distributive egalitarians can appeal to the fact that John now enjoys fewer social resources than Mary in order to justify the conclusion that he is a victim of injustice. On this view, certain relations, such as those that are hierarchical or involve oppression or domination, are unjust purely in virtue of our concern for securing an equal distribution of resources, where that includes a concern for social resources. If correct, this would demonstrate one way in which distributive egalitarianism can fully subsume social egalitarianism.

When evaluating this argument, it is important to distinguish two issues. The first concerns whether distributive egalitarianism is single-handedly capable of delivering the correct verdict that John is a victim of injustice. The second concerns whether distributive egalitarianism can single-handedly provide a plausible explanation of that injustice. We contend that, though distributive egalitarians may specify their theory in such a way as to deliver the correct verdict, it risks mischaracterizing the nature of John's injustice (Axelsen and Bidadanure, forthcoming).

We do not claim, nor do we need to claim, that distributive egalitarianism always mischaracterizes the nature of these kinds of injustices. A concern for an equal distribution of resources can justify a concern for the distribution of some social resources. Perhaps we do well to appeal to distributive egalitarianism to explain the injustice between those who have many valuable friendships and those who have very few. What is significant to our argument is only that distributive egalitarianism cannot justify a concern for all relations, including those present in Couple.

To reveal this problem, let's briefly consider an analogous issue: the wrongness of discrimination. One position states that, when discrimination is 
wrong, it is because of how it affects individuals' resources (LippertRasmussen, 2014). Others deny this. For example, perhaps discrimination can be wrong in virtue of the mental states of the discriminator. ${ }^{28}$ Proponents of the latter view call upon the following kind of case in order to support this conviction:

Cambridge University: Helen is an admissions officer at Cambridge University. As a result of racist prejudices, she is averse to spending time around students with dark skin tone. She recognizes that it would be wrong for her to harm these applicants, and so knows not to reject their applications on these grounds. Instead, and with the hope that they will accept the offer, she uses her connections to ensure that all of these applicants are offered a place at Oxford. ${ }^{29}$

Though we acknowledge that this conclusion is controversial, we take it for granted that Helen acts wrongfully in this case, and that what explains this wrong is Helen's mental state. This case is important because it puts pressure on the idea that we can always explain the wrongness of discrimination in terms of how it affects individuals' resources. At least, this is what we shall assume.

A possible response to cases of this kind is to broaden the notion of 'resources', such that there becomes a sense in which Helen's actions deprive the applicants of certain resources (Lippert-Rasmussen, 2015a; Gheaus, Early View). Perhaps the applicant's resources include not only their opportunities to study at university but also their opportunities to be treated with respect. This move enables one to concede that Helen acts wrongfully, but also to maintain that the discrimination is wrong because of how it affects individuals' resources.

The problem with this is that it mischaracterizes the nature of the wrongness of discrimination (Slavny and Parr, 2015). In Cambridge University, it is misleading to conclude that the applicants are victims of some kind of 'harm', measured in terms of a setback to their resources. Rather, what explains their injustice is something else - plausibly, something relating to Helen's mental states. Any account that failed to distinguish these two distinct sources of wrongdoing would fail to do justice to the complexity of our moral landscape.

This discussion is important because the same is true for those distributive egalitarians who aim to subsume social egalitarianism by broadening the idea of a 'resource' to include social resources. Though this move enables a proponent of the view to accommodate a concern for relations, it 
mischaracterizes the nature of our concern for these relations. It is misleading to conclude that individuals who do not enjoy certain valuable relations, such as John in Couple, are victims of some kind of 'harm', measured in terms of a setback to their resources. ${ }^{30}$ What explains this injustice is something elsesomething not reducible to harm.

The point is not simply that distributive egalitarianism misdiagnoses the nature of John's injustice. Rather, in addition to this, the misdiagnosis parallels the kind of mistake made in Cambridge University by those who holds that, when discrimination is wrong, it is because of how it affects individuals' resources. In both cases, the error consists in interpreting the injustice in terms of a setback to a resource, rather than in other terms.

This conclusion is important as it has the implication that we have two sources of fundamental moral reasons that are distinct, such that we cannot explain our reasons to ensure certain relations between members of the community in terms of our reasons to secure an equal distribution of resources. To be sure, the hybrid account that we defend is in one sense underspecified, in that it does not offer a procedure to resolve conflicts, when they arise, between distributive egalitarianism and social egalitarianism. ${ }^{31}$ Despite this limitation, the hybrid account remains significant because it reveals how and why both kinds of reasons can arise.

\section{A Brief Conclusion}

Our headline conclusion is that distributive egalitarianism and social egalitarianism are not mutually exclusive positions, and that we have reason to accept both claims and to recognize that they provide independent sources of moral reasons. Our contribution is distinctive in that we seek not only to describe the contours of a hybrid view that incorporates insights from both views, but also to excavate its foundations so as to provide more advanced understanding of the complex relationship between the two components.

Throughout, we have been reluctant to engage in detailed analysis of the views held by particular authors who have written about this subject. Our justification for this move is to ensure that we avoid the kind of philosophical point-scoring that too often sets back philosophical and political progress. We have instead tried to focus our energies around constructing an attractive egalitarian vision that draws upon a range of insights from both sides of the debate. We hope that this approach is appealing and we intend for the constructive nature of our conclusions to serve as evidence for this fact. ${ }^{32}$ 


\section{References}

Alexander, Larry, 'What Makes Discrimination Wrongful? Biases, Preferences, Stereotypes, and Proxies', University of Pennsylvania Law Review, 141 (1992), 149-219.

Anderson, Elizabeth, 'What Is the Point of Equality', Ethics, 109 (1999), 287 337.

Anderson, Elizabeth, 'The Fundamental Disagreement between Luck Egalitarians and Relational Egalitarians', Canadian Journal of Philosophy, Supplementary Volume, 36 (2012), 1-23.

Arneson, Richard, 'Equality and Equal Opportunity for Welfare', Philosophical Studies, 56 (1989), 77-93.

Arneson, Richard, 'Luck Egalitarianism: Interpreted and Defended', Philosophical Topics, 32 (2004), 1-20.

Audi, Robert, Reasons, Rights, and Values (Cambridge: Cambridge University Press, 2015).

Axelsen, David V., and Bidadanure, Juliana, 'Unequally Egalitarian: Defending the Egalitarian Credentials of Social Egalitarianism', Critical Review in International Social and Political Philosophy (forthcoming).

Axelsen, David, and Nielsen, Lasse, 'Sufficiency as Freedom from Duress', Journal of Political Philosophy, 23 (2015), 406-26

Brighouse, Harry and Swift, Adam, 'Parents' Rights and the Value of the Family', Ethics, 117 (2006), 80-108.

Brighouse, Harry, and Swift, Adam, Family Values: The Ethics of ParentChild Relationships (Princeton: Princeton University Press, 2014).

Casal, Paula, 'Occupational Choice and the Egalitarian Ethos', Economics and Philosophy, 29 (2013), 3-20.

Chalmers, David, 'Verbal Disputes', Philosophical Review, 120 (2011), 51566.

Cohen, G. A., Self-Ownership, Freedom, and Equality (Cambridge: Cambridge University Press, 1995).

Cohen, G. A., Rescuing Justice and Equality (Cambridge, MA.: Harvard University Press, 2008). 
Cohen, G. A., Why Not Socialism? (Princeton: Princeton University Press, 2009).

Cohen, G. A., On the Currency of Egalitarian Justice: And Other Essays in Political Philosophy (Princeton: Princeton University Press, 2011).

Dworkin, Ronald, Sovereign Virtue: The Theory and Practice of Equality (Cambridge, MA.: Harvard University Press, 2000).

Dworkin, Ronald, Justice for Hedgehogs (Cambridge, MA.: Harvard University Press, 2011).

Fleurbaey, Marc, 'Equal Opportunity or Equal Social Outcome?', Economics and Philosophy, 11 (1995), 25-55.

Fourie, Carina, 'What is Social Equality? An Analysis of Status Equality as a Strongly Egalitarian Ideal', Res Publica, 18 (2012), 107-126.

Gheaus, Anca, 'Hikers in Flip-Flops: Luck Egalitarianism, Democratic Equality and the Distribuenda of Justice', Journal of Applied Philosophy, (Early View).

Gosseries, Axel and Parr, Tom, 'Publicity', Stanford Encyclopedia of Philosophy (Fall 2017 Edition), Edward N. Zalta (ed.), $\mathrm{URL}=<$ https://plato.stanford.edu/entries/publicity/ $>$.

Hellman, Deborah, When Is Discrimination Wrong. (Cambridge, MA.: Harvard University Press, 2008).

Herman, Barbara, 'Being Helped and Being Grateful: Imperfect Duties, the Ethics of Possession, and the Unity of Morality', The Journal of Philosophy, 109 (2013), 391-411.

Laborde, Cecile, 'Republicanism and Global Justice: A Sketch', European Journal of Political Theory, 9 (2010), 48-69.

Lippert-Rasmussen, Kasper, Born Free And Equal: A Philosophical Inquiry into the Nature of Discrimination (Oxford: Oxford University Press, 2014).

Lippert-Rasmussen, Kasper, Luck Egalitarianism (London: Bloomsbury, 2015a).

Lippert-Rasmussen, Kasper, 'Luck Egalitarians versus Relational Egalitarians: On the Prospects of a Pluralist Account of Egalitarian Justice', Canadian Journal of Philosophy, 45 (2015b), 220-41. 
Lasse Nielsen, 'What Is Our Real Concern with Real Inequality?', Policy Studies Journal, (Online First).

Miller, David, 'Equality and Justice', Ratio, 10 (1997), 222-237.

Olsaretti, Serena, 'Responsibility and the Consequences of Choice', Proceedings of the Aristotelian Society, 109 (2009), 165-88.

Rawls, John, Political Liberalism (New York: Columbia University Press, 1996).

Rawls, John, 'The Idea of Public Reason Revisited', The University of Chicago Law Review, 64 (1997), 765-807.

Rawls, John, A Theory of Justice: Revised Edition (Cambridge, MA.: Harvard University Press, 1999).

Raz, Joseph, The Morality of Freedom (Oxford: Clarendon Press, 1986).

Raz, Joseph, Practical Reason and Norms (Princeton: Princeton University Press, 1990).

Scanlon, Thomas, What We Owe to Each Other (Cambridge: MA.: Harvard University Press, 1998).

Scanlon, Thomas, Moral Dimensions: Permissibility, Meaning, Blame (Cambridge, MA.: Harvard University Press, 2008).

Scheffler, Samuel, 'Choice, Circumstance, and the Value of Equality', Politics, Philosophy \& Economics, 4 (2005), 5-28.

Scheffler, Samuel, 'The Practice of Equality', in Carina Fourie, Fabian Schuppert, and Ivo Wallimann-Helmer (eds), Social Equality: On What It Means to be Equals (Oxford: Oxford University Press, 2015), 20-44.

Schemmel, Christian, 'Why Relational Egalitarians Should Care About Distributions', Social Theory and Practice, 37 (2011), 365-90.

Schemmel, Christian, 'Distributive and Relational Equality', Politics, Philosophy, and Economics, 11 (2012), 123-48.

Segall, Shlomi, 'Incas and Aliens: The Truth in Telic Egalitarianism', Economics and Philosophy, 32 (2016), 1-19.

Slavny, Adam and Parr, Tom, 'Harmless Discrimination', Legal Theory, 21 (2015), 100-14. 
Stemplowska, Zofia, 'Responsibility and Respect: Reconciling Two Egalitarian Visions' in Carl Knight and Zofia Stemplowska (eds), Responsibility and Distributive Justice (Oxford: Oxford University Press, 2011), 115-35.

Stemplowska, Zofia, 'Rescuing Luck Egalitarianism', Journal of Social Philosophy, 44 (2013), 402-19.

Stemplowska, Zofia, 'Rarely Harsh and Always Fair: Luck Egalitarianism and Unhealthy Choices' in Matthew Liao and Collin O'Neill (eds), Current Controversies in Bioethics (London: Routledge, 2016), 149-59.

Tadros, Victor, 'Rights and Security', in Rowan Cruft, Matthew Liao, and Massimo Renzo (eds), The Philosophical Foundations of Human Rights (Oxford: Oxford University Press, 2015).

Temkin, Larry, Inequality (Oxford: Oxford University Press, 1993).

Williams, Andrew, 'Liberty, Equality, and Property' in John S. Dryzek, Bonnie Honig, and Anne Phillips (eds), The Oxford Handbook of Political Theory (Oxford: Oxford University Press, 2006), 488-506.

Williams, Andrew, 'Justice, Incentives, and Constructivism', Ratio, 21 (2008), 476-93.

Wolff, Jonathan, 'Fairness, Respect, and the Egalitarian Ethos', Philosophy \& Public Affairs, 27 (1998), 97-122.

\footnotetext{
${ }^{1}$ Proponents of this view include Arneson (1989); Cohen (2011); Lippert-Rasmussen (2015); and Temkin (1993).

${ }^{2}$ Proponents of this view include Anderson (1999); and Scheffler (2003).

${ }^{3}$ Important exceptions include Schemmel (2011 and 2012). Schemmel's view is consistent with our own. Our task is more ambitious in that we excavate deeper philosophical foundations of this kind of view. For other attempts, see Lippert-Rasmussen (2015b); and Wolff (1998).

${ }^{4}$ For a defence of the former view, see Arneson (1989). For an alternative, see Cohen (2011). ${ }^{5}$ For a defence of the former view, see Anderson (1999).

${ }^{6}$ For a defence of a broad site of application, see Scheffler (2015).

${ }^{7}$ For illustration, see many of the contributions in Rowan Cruft, Matthew Liao, and Massimo Renzo (2015). The exception to this is chapter 24, 'Rights and Security', in which Victor Tadros eschews conceptual disputes about human rights, and instead pursues a line analogous to the one that we pursue in this section.

${ }^{8}$ For example, Anderson claims that this disagreement is fundamentally about 'how to conceive of equality' (2012: 1). Scheffler writes that distributive and relational views of
} 
equality 'do not exhaust the possible interpretations of equality.... According to the fist view, equality is an essentially distributive value.... According to the second, relational view, equality is an ideal governing certain kinds of interpersonal relationships' (2015: 21). David Miller also suggests that 'There is...uncertainty about the relationship between the concepts of equality and justice... On one side are those who think that the two concepts must be kept radically separate... One the other side stand those who believe that the two values are the one and the same' (1997: 222-3). Though Dworkin also presents his view as one about the nature of equality, he is explicit that our analysis of political concepts should be informed by our normative commitments (2011: part two).

${ }^{9}$ The possibility of verbal disputes might be unavoidable, since people might mean different things by 'reasons'. Because this is unlikely, we put aside this complication.

${ }^{10}$ By stating these positions in a way that does not include the key term 'equality', we adopt what Chalmers calls the method of elimination (2011: 526).

"There is a further question about the scope of the community in question-is it national, global, or something else? Our analysis is compatible with a wide range of answers to this question.

${ }^{12}$ Our claim is less extreme than that made by Joseph Raz who, when discussing the concept of freedom, writes: 'It is only important to remember that that concept is a product of a theory or a doctrine consisting of moral principles for the guidance and evaluation of political actions and institutions. One can derive a concept from a theory but not the other way round' (1986: 16). We thank an anonymous reviewer for prompting us to clarify this feature of our analysis.

${ }^{13}$ It is an attractive feature of our approach that it does not rely on any specific account of the relationship between reasons and concepts. This is because this topic is subject to intense philosophical dispute. For discussion, see Audi (2015); and Scanlon (1998: ch. 2).

${ }^{14}$ See Cohen (2011). Of course, other distributive egalitarians welcome this language. See Arneson (2004), as well as Larry Temkin's canonical definition of luck egalitarianism: 'It is bad (unfair and unjust) for some to be worse off than others through no fault of their own' (1993: 13).

${ }^{15}$ For instance, Cohen writes that his 'fundamental concern is neither the basic structure of society, in any case, nor people's individual choices, but the pattern of benefits and burdens in society' (2008: 126).

${ }^{16} \mathrm{We}$ are interested in cases of this kind because of what they teach us about the more general principles that should guide the arrangement of society's major social institutions.

${ }^{17}$ We bracket the issue of what counts as an equal distribution, as well as the fact that their mother's wishes may play some role in determining how to distribute the inheritance.

${ }^{18}$ For one, we put aside the fact that more equal distributions may be instrumentally valuable to reducing the chances of abuses of political power, which in turn may be necessary for certain relations to exist. See Laborde (2010: 52). For discussion of how other, specific kinds of inequalities-such as inequalities pertaining specifically to hiring processes-may undermine certain valuable social relationships, see Nielsen (Online First).

${ }^{19}$ We thank Lisa Herzog and an anonymous reviewer for improving our understanding of these issues.

${ }^{20}$ These two conditions might interact in different ways. On an additive view, the value of justificatory community varies with the degree to which each condition is satisfied. On a constitutive view, the value of justificatory community simply depends upon both conditions being satisfied to some minimal level. It is also possible to construct hybrid views that incorporate elements of both. 
${ }^{21}$ Other distributive theories may also claim to play this role, including distributive prioritarianism, desert-theories, and a whole host of alternatives. Since the subject of this paper is the relationship between distributive egalitarianism and social egalitarianism, we put aside these other disputes.

${ }^{22}$ These reasons may be overdetermined. See Rawls (1997: 793).

${ }^{23}$ For discussion of civic friendship, see Rawls (1996: esp. Introduction and Lecture I); and Gosseries and Parr (2017: section 3).

${ }^{24}$ Trivial inequality might still be objectionable under certain circumstances, such as when they express offensive attitudes.

${ }^{25}$ Zofia Stemplowska claims that 'the main battle' between these two views appears to centre on such cases (2011: 120). We thank an anonymous reviewer for encouraging us to include discussion of these issues.

${ }^{26}$ This is not to say that none of our reasons to secure an equal distribution of resources derives from our concern for certain relations. Rather, our analysis supports the more modest claim that not all do.

${ }^{27}$ We take this case from Lippert-Rasmussen (2015: 195). For a similar argument, see Gheaus, (Early View).

${ }^{28}$ Other views are possible. For example, both Deborah Hellman and Thomas Scanlon locate the wrongness of discrimination in the objective meaning expressed by discriminatory acts. See Hellman (2008) and Scanlon (2008).

${ }^{29}$ For this case, see Slavny and Parr (2015). See also Alexander (1992).

${ }^{30}$ Commenting on why certain relations between individuals are intrinsically valuable, Martin O'Neill similarly concludes that 'The existence of these kinds of social relations should itself be seen as intrinsically valuable, independent of the positive effects that such relations may have for individual welfare' (2008: 130). For helpful discussion of this quote, see Tomlin (2015: 164).

${ }^{31}$ To admit that our reasons to distribute resources equally and our reasons to ensure certain relations between members of the community can conflict is not to concede that distributive egalitarianism and social egalitarianism are mutually exclusive. To say that reason $\mathrm{P}$ and reason $\mathrm{Q}$ are conflicting reasons is to say that we have both reasons, but that they point in different directions. To say that reason $\mathrm{P}$ and reason $\mathrm{Q}$ are mutually exclusive is to say that we cannot have both reasons - at least one is not in fact a reason at all.

${ }^{32}$ For helpful comments and advice, we thank the Editors of Political Studies, two anonymous referees for this journal, and an audience at the 2015 Amazing Summer Workshop at the LSE, as well as Sara Amighetti, David Axelsen, Paul Bou-Habib, Clare Burgum, Matthew Clayton, James Christensen, Sandy Dewar, Kasper Lippert-Rasmussen, Lasse Nielsen, Adam Slavny, Zofia Stemplowska, Adam Swift, Patrick Tomlin, Andrew Walton, Andrew Williams, and Han Van Wietmarschen. 